\title{
The effect of regular aerobic activity on cortisol levels in female Wistar rats
}

\author{
Arbnore Ibrahimaj Gashi ${ }^{1 \oplus}$, Arjeta Azemi ${ }^{2 \oplus}$, Vujica Zivkovic ${ }^{3}$, Serjoza Gontarev ${ }^{3}$, Icko Gjorgovski ${ }^{4}$
}

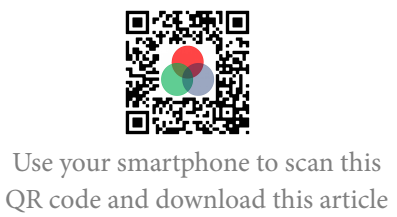

${ }^{1}$ Universityof Prishtina "Hasan Prishtina" Faculty of Medicine, Physiotherapy department, Prishtina, Kosovo

${ }^{2}$ Alma Mater Europaea Campus college of Medical Science "Rezonanca" Prishtina, Kosovo

${ }^{3}$ University "Ss. Cyril and Methodius" Faculty of Physical Education, Sport and Health" Skopje, North Macedonia

${ }^{4}$ University "Ss. Cyril and Methodius", Faculty of Natural Sciences and Mathematics, Institute of Biology, Skopje, North Macedonia

\section{History}

- Received: Oct 14, 2020

- Accepted: Feb 17, 2021

- Published: Feb 28, 2021

DOI : 10.15419/bmrat.v8i2.660

\section{Check for updates}

\section{Copyright}

(c) Biomedpress. This is an openaccess article distributed under the terms of the Creative Commons Attribution 4.0 International license.

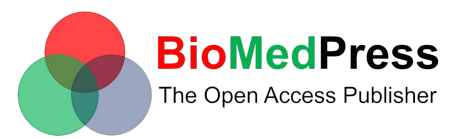

\begin{abstract}
Introduction: Physical inactivity has been identified as a major risk factor for global mortality, causing approximately 2 million deaths globally, whereas the physical activity of moderate intensity has significant benefits for health. Exposure to stress results in changes in the endocrine and autonomic nervous systems, as well as behavioral changes which allow an organism to adapt to environmental changes. This study aimed to assess changes in cortisol levels and body temperature in rats after forced swim tests. Methods: Female Wistar rats were divided into two groups: a control group (n $=10$; not subjected to a forced swim test) and an experimental group ( $n=10$; subjected to a forced swim test). The forced swim test (60 - 90 min) was given to the experimental group for 21 days. Body temperature was measured rectally every day, and blood was taken from the animals on the $1^{s t}, 7^{t h}, 14^{\text {th }}$, and $21^{s t}$ days of the experiment to determine cortisol levels using a Mouse/Rat Cortisol ELISA protocol. Results: The results showed a statistically significant difference in the cortisol level between the groups on day 21 ( $p<0.05)$. We found a significant reduction in the recurrent temperature after exposure to physical stress. Conclusions: Regular aerobic activity at a submaximal level for 21 days can reduce the hormonal stress response in female Wistar rats.

Key words: aerobic activity, cortisol, female rats, forced swim test
\end{abstract}

\section{INTRODUCTION}

Understanding the effect of stress hormones will provide an idea of how stressors can influence homeostasis. For evaluation of stress hormones in experimental studies, the most frequently used subjects have been rats since they are very sensitive to stress ${ }^{1}$. Besides, the degree of activation of the hypothalamicpituitary-adrenal (HPA) axis is related to the intensity of stress. Animal model studies usually involve physical activities that simulate what human are exposed to, with the most frequently activities being treadmill running and swimming ${ }^{2}$.

Since animal respond to stress by increasing their glucocorticoid levels, there has been considerable interest in measuring these hormones because the intensity and duration of stress may lead to pathological changes. However, the positive effect of stress (eustress) and the negative effect (distress) have been equally discussed ${ }^{3}$. Hormones are extremely powerful molecules in the human body. They are used for communication between tissues, with the ultimate goal of regulating body processes and behaviors. There are many different hormones in the human body and each has a specific function ${ }^{4}$.

Cortisol level are regulated by the HPA axis from neuroendocrine feedback, a circuit could be activated by physiological stimuli such as stress, illness, depression, and Cushing's syndrome, or by exercise ${ }^{5}$. According to the literature, aerobic exercise shows comparable therapeutic effects as a pharmacological treatment or psychological therapy in treating patients with depressive disorders ${ }^{6}$. Measuring the HPA axis activity via the plasma cortisol level is a useful method for evaluating the effects of stress on animals because it is stimulated by the onset of perceived stress ${ }^{7}$.

This study aimed to evaluate the effect of regular aerobic physical activity on cortisol levels of female white laboratory (Wistar) rats for 21 days.

\section{MATERIALS - METHODS}

\section{Ethical statement}

All experimental procedures were performed in accordance with the Manual for Care and Use of Laboratory Animals, and were approved by the Ethics Committee of the Macedonian Center for Bioethics at the University of St. Kiril and Metodij, in Skopje, North Macedonia (protocol number 2401-592, 2017). The biomedical research recommendations for animal use was issued by the Council of International Organizations for Medical Sciences. The anesthetics were applied following the EU Directive's standards, Directive 86/609/ EEC. 


\section{Experimental animals}

This experimental study was conducted at the Faculty of Natural Sciences and Mathematics of the Institute of Biology in Skopje, North Macedonia. In this study, experimental animals included female white laboratory rats from the Wistar strain $(n=64)$ at the age of 4 -5 months with a body mass of $220 \pm 20 \mathrm{~g}$. During the study, the animals were exposed to a standard food and water diet regimen (ad libitum) and were kept in a room under a constant light regime of $12 \mathrm{~h}$ (06:00 to 18:00) of light and $12 \mathrm{~h}$ of the dark at a thermoneutral temperature of $26^{\circ} \mathrm{C}$. The total number of animals used in this study was 20 , and they were divided into two groups of 10 animals randomly. The first group was the control group of rats $(n=10)$, which were not subjected to the forced swim tests, and the second group of rats $(n=10)$ were subjected to forced swim tests. The gender was specific with only female rats. Exclusion criteria were rats older than 5 months and rats with physical impairments.

\section{Experimental procedure}

The experimental group of animals $(\mathrm{n}=10)$ was exposed to forced swim tests for 21 days. For the remaining 7 days up to the end of the experiment, 5 rats from the experimental group continued to swim until day 21 while 5 rats were allowed to rest. The water temperature was measured before and after swimming. To determine the level of cortisol, the blood was collected from the tail of the rats on the $1^{s t}, 7^{t h}$, and $14^{\text {th }}$ days of the experiment. On day 21 , the blood from the abdominal aorta was collected. The serum analyses were made using a Mouse/Rat Cortisol ELISA protocol. The duration of the entire experiment was 22 days.

\section{Forced swimming test}

Rats were exposed to a forced swim test, with the swimming program consisting of two phases: adaptation and training. In the first week (adaptation), the rats swam 60 - 90 min per day for 6 days (1 week). The training period commenced at the beginning of the second week of swimming, and its duration was progressively increased from $50 \mathrm{~min}$ to approximately 90 min per day. Rats were exposed to the swimming test between 08:30 and 12:00 AM. This intensity was maintained until the end of the training program, which lasted 6 days per week for a total of three weeks (21 days) from Monday-Saturday (on Sunday, there were no activities for the experimental rats).

Forced swimming stress was induced in the rats by forcing them to swim in a cylindrical swim tank which

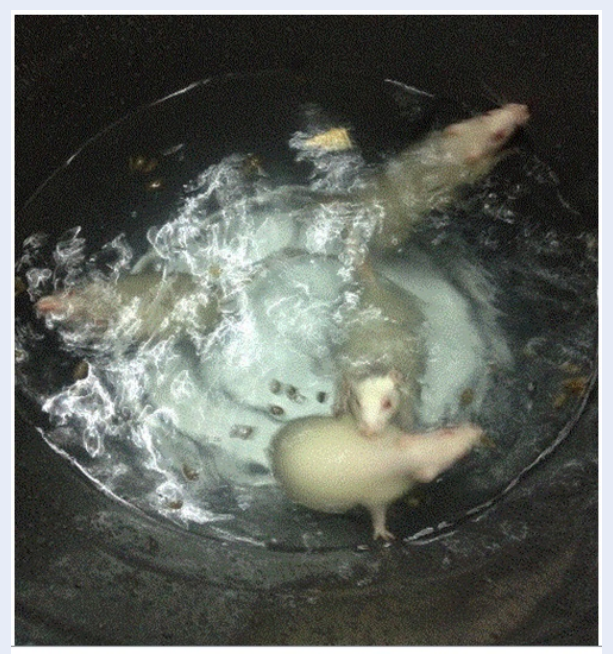

Figure 1: Wistar female rats exposed to the forced swim test.

was filled with tepid water $\left( \pm 34^{\circ} \mathrm{C}\right)$. All swimming protocols were recorded via a video camera and a photo camera (Figure 1). The length of the cylindrical swim tank was approximately $80-90 \mathrm{~cm}$. The tank was filled with water to a depth of $50-60 \mathrm{~cm}$, a depth which exceeded the length of the rats, including their tail (the length of the rats were approximately $40 \mathrm{~cm}$ ). The width of the tank was $60 \mathrm{~cm}$.

Body temperature was measured rectally using a digital thermometer before and after the forced swim test each day on days 5 - 10, $13-18,20$, and 21. Additionally, a description of statistics for temperature was made for each day. During the procedure for measuring body temperature before the swim test, the rats were immobilized with one hand, with their tails displaced, and the thermometer was penetrated into the rectum for approximately $10 \mathrm{~s}$. The same procedure was applied after the swim test to measure their body temperature (Figure 2).

\section{Collection and preparation of blood serum and plasma}

The procedure for collecting blood was always performed in the morning and before the forced swim tests. Blood was taken from the rats' tail vein on days 1,7 and 14, and then the rats were awakened; there was no need for anesthesia. In brief, a small nick over the lateral tail vein using a sterile scalpel blade was made approximately 2 - $3 \mathrm{~mm}$ from the tip of the tail. When the nick was deep enough, blood started welling up from the nick immediately. The blood was collected by allowing it to drop into a collection tube. The tail was gently stroked from the tail 

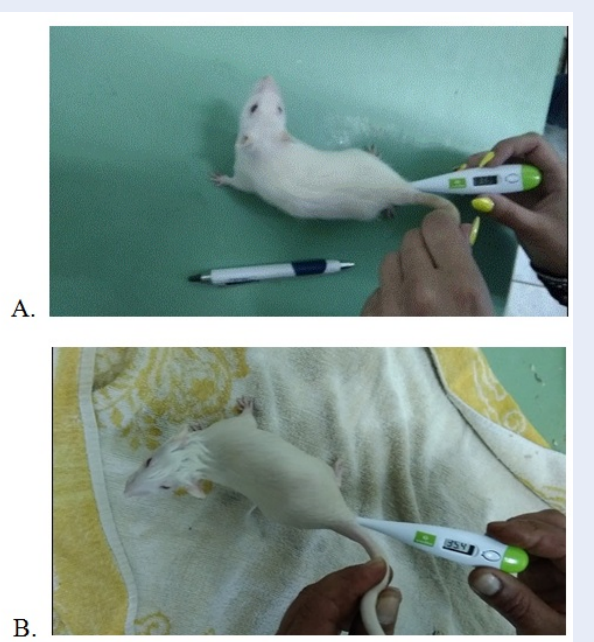

Figure 2: Measurement of body temperature of the rats before (A) and after (B) the forced swim tests.

base toward the tail end to encourage blood flow. The amount of blood collected was $1.5 \mathrm{~mL}$, and it was allowed to clot for $30 \mathrm{~min}$ at room temperature. The serum was separated by centrifugation at $3000 \mathrm{rpm}$ for $15 \mathrm{~min}$. After centrifugation, the amount of serum collected was $0.75 \mathrm{~mL}$ and it was subsequently stored at $-20^{\circ} \mathrm{C}$. To measure the concentration of cortisol, we used a Mouse/Rat Cortisol kit (Sigma-Aldrich, St. Louis, MO, USA), according to its manufacturer's protocol (ELISA SIG-ALD SE120082). On day 21, all experimental rats were sacrificed, and blood was collected from the abdominal artery. Whole blood was collected into centrifuge tubes containing potassiumEDTA (as an anticoagulant) and centrifuged immediately for $3000 \mathrm{rpm}$ for $15 \mathrm{~min}$. After centrifugation, the amount of plasma collected was 5-6 mL, and the sample was subsequently stored at $-20^{\circ} \mathrm{C}$. The plasma samples were then subjected to the cortisol estimation similarly using the Mouse/Rat Cortisol ELISA.

\section{Statistical analyses}

Data were analyzed using the SPSS 22.0 software package for Windows (SPSS Inc., Chicago, IL, USA). Basic descriptive statistics were computed. The normality distribution of the data was determined using the skewness, kurtosis, and Kolmogorov-Smirnov method. One-Way Repeated-Measures ANOVA was used to analyze differences in variables, and the least significant difference (LSD) test was performed.

\section{RESULTS}

\section{Temperature}

Based on the temperature measurements obtained before and after the completion of the forced swim tests, the following results were obtained, which were statistically processed. As shown in Figure 3, the rectal temperature of the rats before the onset of physical stress was in the interval of normal values, but there was a noticeable decrease in the temperature after exposure to physical stress. According to the figure, there was a difference between the rectal temperature measured on the $21^{\text {st }}$ day for the same rats. Moreover, as shown in Table 1, there were statistically significant differences in all comparisons.

\section{Cortisol}

According to Table 2, the values of skewness of the cortisol variable in the control group $(\mathrm{Sk}=-0.04)$ of rats that swam for 21 days $(\mathrm{Sk}=-0.55)$ and in rats that rested from the $14^{\text {th }}$ to $21^{\text {st }}$ day $(\mathrm{Sk}=-0.02)$ were within the limits of the recommended values (from -1 to +1$)$, indicating that the distribution of the results was approximately symmetric. Mild negative asymmetry was observed for rats that swam until day $7(\mathrm{Sk}=-1.37)$.

Based on the calculated coefficients of variability, the homogeneity at all collected timepoints was satisfactory. The lowest level of homogeneity was observed on the $7^{\text {th }}$ day of swimming $(\mathrm{CV}=5.56)$, whereas the highest level of dispersion of results was observed on the $21^{\text {st }}$ day after swimming $(\mathrm{CV}=43.82)$.

Based on the standard deviations (SD) at all timepoints, there was no statistically significant deviation of the results from the arithmetic mean. The standard error values indicated a minimum dispersion because there was no significance in relation, proportionally, to the corresponding standard deviation.

According to the results from the Kolmogorov-Smirnov method, as shown in Table 3, in all groups the results were normally distributed $(p>0.20)$. Although this was a small selective sample of subjects, the results of the analysis indicated that there was a normal distribution at all timepoints. Thus, we concluded that the degree of normality of the distributions of the applied variables satisfied the necessary methodological and statistical criteria for the application of correct and justified parametric statistical procedures for further processing of the data. Indeed, this created conditions for sufficient precise scientific determination, analysis, and comparison of data.

As shown by the values in Table 4, there was no statistically significant influence of time since Wilks' 
Table 1: Comparison of the mean values of temperature

\begin{tabular}{|c|c|c|c|c|c|c|c|c|c|}
\hline & & & Mean & SD & S.E & Lower & Upper & $t$ & Sig. \\
\hline Pair 1 & $\begin{array}{l}\text { S_day5 } \\
\text { F_day5 }\end{array}$ & - & 4.34 & 1.06 & 0.33 & 3.58 & 5.10 & 12.97 & 0.000 \\
\hline Pair 2 & $\begin{array}{l}\text { S_day6 } \\
\text { F_day6 }\end{array}$ & - & 3.51 & 0.85 & 0.27 & 2.90 & 4.12 & 13.09 & 0.000 \\
\hline Pair 3 & $\begin{array}{l}\text { S_day7 } \\
\text { F_day7 }\end{array}$ & - & 2.29 & 0.83 & 0.26 & 1.70 & 2.88 & 8.76 & 0.000 \\
\hline Pair 4 & $\begin{array}{l}\text { S_day8 } \\
\text { F_day8 }\end{array}$ & - & 3.37 & 0.95 & 0.30 & 2.69 & 4.05 & 11.26 & 0.000 \\
\hline Pair 5 & $\begin{array}{l}\text { S_day9 } \\
\text { F_day9 }\end{array}$ & - & 2.53 & 1.09 & 0.36 & 1.69 & 3.37 & 6.96 & 0.000 \\
\hline Pair 6 & $\begin{array}{l}\text { S_day10 } \\
\text { F_day10 }\end{array}$ & - & 3.47 & 0.70 & 0.23 & 2.93 & 4.01 & 14.82 & 0.000 \\
\hline Pair 7 & $\begin{array}{l}\text { S_day13 } \\
\text { F_day13 }\end{array}$ & - & 3.80 & 0.94 & 0.31 & 3.08 & 4.52 & 12.12 & 0.000 \\
\hline Pair 8 & $\begin{array}{l}\text { S_day14 } \\
\text { F_day14 }\end{array}$ & - & 3.94 & 0.88 & 0.39 & 2.85 & 5.03 & 10.05 & 0.001 \\
\hline Pair 9 & $\begin{array}{l}\text { S_day15 } \\
\text { F_day15 }\end{array}$ & - & 2.98 & 0.55 & 0.25 & 2.29 & 3.67 & 12.03 & 0.000 \\
\hline $\begin{array}{l}\text { Pair } \\
10\end{array}$ & $\begin{array}{l}\text { S_day16 } \\
\text { F_day16 }\end{array}$ & - & 3.14 & 0.92 & 0.41 & 1.99 & 4.29 & 7.60 & 0.002 \\
\hline $\begin{array}{l}\text { Pair } \\
11\end{array}$ & $\begin{array}{l}\text { S_day17 } \\
\text { F_day17 }\end{array}$ & - & 3.58 & 0.33 & 0.15 & 3.17 & 3.99 & 24.47 & 0.000 \\
\hline $\begin{array}{l}\text { Pair } \\
12\end{array}$ & $\begin{array}{l}\text { S_day18 } \\
\text { F_day18 }\end{array}$ & - & 3.24 & 0.75 & 0.33 & 2.31 & 4.17 & 9.70 & 0.001 \\
\hline Pair 1 & $\begin{array}{l}\text { S_day20 } \\
\text { F_day20 }\end{array}$ & - & 1.78 & 1.10 & 0.55 & 0.02 & 3.53 & 3.22 & 0.049 \\
\hline Pair 2 & $\begin{array}{l}\text { S_day21 } \\
\text { F_day21 }\end{array}$ & - & 4.40 & 1.38 & 0.69 & 2.21 & 6.59 & 6.38 & 0.008 \\
\hline
\end{tabular}

There was statistically significant difference for all comparison days. S-start, F-finish.

Table 2: Statistical data of cortisol levels among the groups

\begin{tabular}{lcccccccc}
\hline CORTISOL & Mean & Min & Max & SD & CV & s.e. & Skew & Kurtos \\
CONTROL & 0.43 & 0.34 & 0.53 & 0.06 & 14.17 & 0.02 & -0.04 & -0.13 \\
7 DAY SWIM & 0.39 & 0.35 & 0.42 & 0.02 & 5.56 & 0.01 & -1.37 & 3.04 \\
REST FROM DAY 14 & 0.36 & 0.29 & 0.42 & 0.05 & 13.95 & 0.02 & -0.02 & -1.88 \\
21 DAY SWIM & 0.34 & 0.12 & 0.49 & 0.15 & 43.82 & 0.05 & -0.55 & -1.47 \\
\hline
\end{tabular}

Mean cortisol levels among the groups: control group (0.43) experimental group of rats exposed to an forced swim test until day 7 (0.39), the group of rats that rested from day $14(0.36)$, and the group of rats that swam until day $21(0.34)$. There was no statistically significant deviation of the results from the arithmetic mean. 


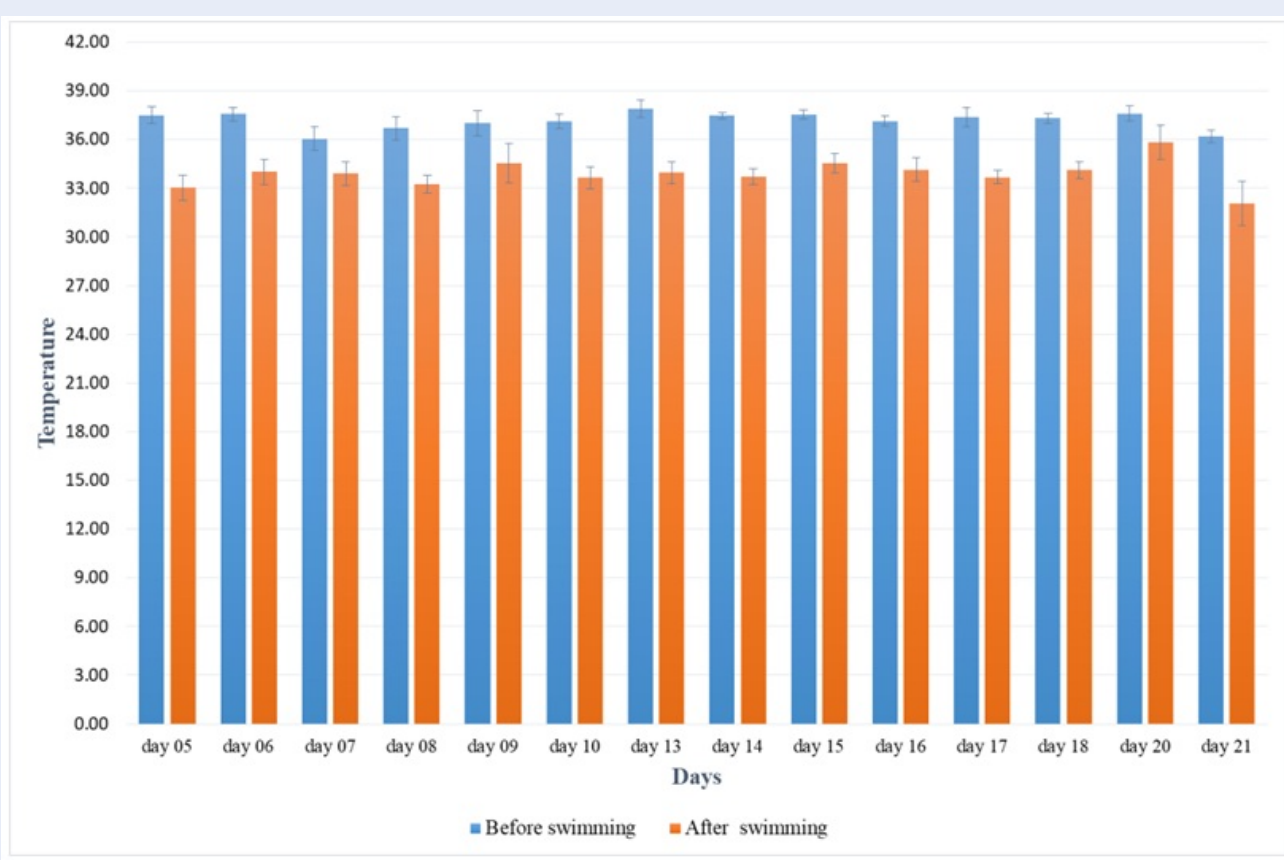

Figure 3: Comparison of the mean values of the temperature measured rectally before and after the forced swim test.

Table 3: Results of the Kolmogorov-Smirnov method for cortisol

\begin{tabular}{lcc}
\hline CORTISOL & $\max \mathbf{D}$ & K-S \\
CONTROL & 0.150 & $\mathrm{p}>0.20$ \\
7 DAY SWIM & 0.223 & $\mathrm{p}>0.20$ \\
REST FROM DAY 14 & 0.229 & $\mathrm{p}>0.20$ \\
21 DAYS SWIM & 0.210 & $\mathrm{p}>0.20$ \\
\hline
\end{tabular}

For all groups, the results were normally distributed $(\mathrm{p}>0.20)$.

Lambda $=0.348$ and the degrees of freedom was $\mathrm{F}(3.6)=63.221$, which provided statistical significance at the level of $Q=0.079$. The size of the partial effect of the determinants was at a high value of 0.652 . To determine whether there were statistically significant differences among the investigated groups at the univariate level for the cortisol variable, post-hock tests (LSD test) were applied. Our analyses of the tests are shown in Table 5 and Figure 4. According to the arithmetic means and statistical significance level, any statistically significant differences were observed only between the control group and the group of rats that swam for 21 days $(\mathrm{p}<0.05)$.

The arithmetic means indicated that rats who swam for 21 days had lower serum cortisol values (0.34) than the control group of rats (0.43). There were no statistically significant differences between the other groups.

According to the arithmetic means, the rats that swam for 7 days (0.39) and the rats that rested from day 14 until day 21 showed lower serum cortisol values (0.36) relative to the control group.

\section{DISCUSSION}

This study aimed to observe the in vivo influence of the forced swim tests during a 21 - day span on the stress hormone cortisol. Exposure to stress results in changes in the endocrine system and the autonomic nervous system, as well as behavioral changes that allow the organism to adapt to environmental changes ${ }^{8}$.

According to literature, the normal rectal temperature in rats measured with a mercury thermometer ranges from $37.2{ }^{\circ} \mathrm{C}$ to $38.1^{\circ} \mathrm{C}$, with an average of 
Table 4: Results of one-factor analysis of variance of repeated measurements for cortisol

\begin{tabular}{llcccccc}
\hline Effect & & Value & F & Hypothesis df & Error df & Sig. & Partial Eta Squared \\
Time & Pillai's Trace & 0.652 & 3.744 & 3.000 & 6.000 & 0.079 & 0.652 \\
& Wilks' Lambda & 0.348 & 3.744 & 3.000 & 6.000 & 0.079 & 0.652 \\
& Hotelling's Trace & 1.872 & 3.744 & 3.000 & 6.000 & 0.079 & 0.652 \\
& Roy's Largest Root & 1.872 & 3.744 & 3.000 & 6.000 & 0.079 & 0.652 \\
\hline
\end{tabular}

No statistical significant because Wilks' Lambda $=0.348$, the degrees of freedom was $\mathrm{F}(3.6)=63.221$, and the statistical significance was at the level of $\mathrm{Q}=0.079$.

Table 5: Cortisol results from post hock tests

\begin{tabular}{|c|c|c|c|c|c|c|}
\hline \multicolumn{2}{|c|}{ (I) Time } & \multirow{2}{*}{$\begin{array}{c}\text { Mean Difference } \\
(\mathrm{I}-\mathrm{J})\end{array}$} & \multirow[t]{2}{*}{ Std. Error } & \multirow[t]{2}{*}{ Sig.a } & \multicolumn{2}{|c|}{ 95\% Confidence Interval for Difference } \\
\hline & & & & & Lower Bound & Upper Bound \\
\hline \multirow[t]{3}{*}{1} & 2 & 0.034 & 0.020 & 0.124 & -0.012 & 0.079 \\
\hline & 3 & 0.068 & 0.033 & 0.070 & -0.007 & 0.143 \\
\hline & 4 & $0.091^{*}$ & 0.040 & 0.050 & -0.001 & 0.184 \\
\hline \multirow[t]{3}{*}{2} & 1 & -0.034 & 0.020 & 0.124 & -0.079 & 0.012 \\
\hline & 3 & 0.034 & 0.019 & 0.110 & -0.010 & 0.078 \\
\hline & 4 & 0.058 & 0.049 & 0.272 & -0.055 & 0.170 \\
\hline \multirow[t]{3}{*}{3} & 1 & -0.068 & 0.033 & 0.070 & -0.143 & 0.007 \\
\hline & 2 & -0.034 & 0.019 & 0.110 & -0.078 & 0.010 \\
\hline & 4 & 0.023 & 0.060 & 0.709 & -0.115 & 0.162 \\
\hline \multirow[t]{3}{*}{4} & 1 & $-0.091^{*}$ & 0.040 & 0.050 & -0.184 & 0.001 \\
\hline & 2 & -0.058 & 0.049 & 0.272 & -0.170 & 0.055 \\
\hline & 3 & -0.023 & 0.060 & 0.709 & -0.162 & 0.115 \\
\hline
\end{tabular}

LSD: least significant difference test, ${ }^{*}$ Statistically significant difference $(\mathrm{p}<0.05)$.

$37.6{ }^{\circ} \mathrm{C}^{9,10}$. Based on our results, the rectal temperature of the rats in our study prior to initiation of physical stress (forced swimming) was within the limits of the normal values. Responses to stress are common in various mammalian species, including rodents, pigs, squirrels, baboons and chimpanzees ${ }^{11}$. We found lower measured temperature values for the rats after exposure to physical stress in response to it. This resulted from the removal of heat from the body during physical exercise and the need for higher energy in the muscles during swimming, and these results are consistent with those of other authors ${ }^{12}$.

According to our statistical analysis of the concentrations obtained in the serum test, there was a significant difference in the control and blood taken on day 14 , and the control and serum collected on day 21 of swimming. Statistically significant differences were determined only between the control group and the group that swam for 21 days, and these data are consistent with other studies ${ }^{13}$. A prior study had subjected Wistar male rats to treadmill running for 21 days for $60 \mathrm{~min} /$ day; the level of cortisol was found to be lower when compared to that of the control group ${ }^{14}$. Therefore, we can see the importance of duration of aerobic activity (from $60 \mathrm{~min}$ per day), and our results confirm other data regarding the duration of aerobic activity and the positive impact of the level of cortisol.

Recent authors have reported contradictory results regarding the cortisol levels after 21 days of physical activity, even though the methodology was approximately the same. Only the duration of aerobic activity was different; thus, this may be one important factor for the contradictory results ${ }^{15}$. If we look at studies conducted in humans, there is evidence that participants with higher levels of aerobic fitness show lower levels of cortisol after physical and mental 


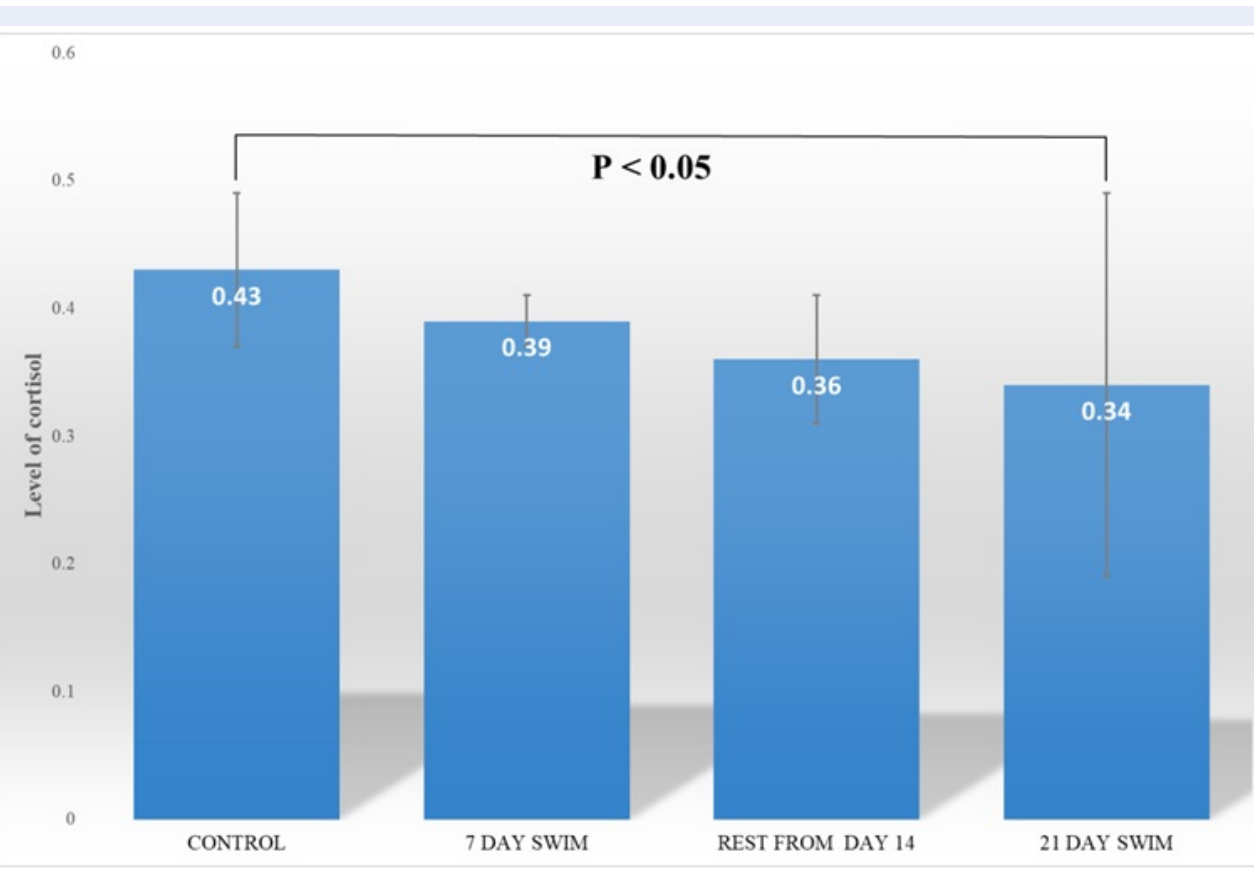

Figure 4: Comparison of cortisol levels among groups. Statistically significant differences between the control group and the group of rats that were exposed to the forced swim test for 21 days $(p<0.05)$.

stress ${ }^{16}$, implying that people who are well-fit will exhibit stronger reactivity and faster recuperation when faced with stressful events ${ }^{17}$. However, this is not certain because according to evidence, over-trained athletes can also experience fatigue, mood problems, and depression ${ }^{18}$.

Pain perception is another factor that should be considered in people, and many studies have been conducted regarding pain threshold. It is well-know that exercise and stress can both influence pain perception ${ }^{19}$. According to another study, one group of rats was exposed to exhaustion exercises, and the results showed that rats who had a higher aerobic capacity experienced a higher pain threshold ${ }^{20}$. These results confirm that physical activity ha a positive effect on reducing musculoskeletal pain by increasing the pain threshold.

Regarding the relation between cortisol levels, physical activity, and the aging process, some authors have conducted a review of studies to analyze the influence of chronic exercise on serum cortisol in older people. According to their results, those authors concluded that chronic exercise has an influence on serum cortisol levels in older people ${ }^{21}$. Intensive exercise affects brain bioenergetics, inflammation and neurogenesis; moreover, intense exercise above the lactate threshold may benefit the aging brain ${ }^{6}$.
Regarding our data that showed lower cortisol levels in female rats 21 days after swimming, the results are consistent with those from another study that showed lower levels of stress hormone in female rats who were exposed to exercise for 21 days for approximately 1 hour/day ${ }^{22}$. The results confirm that regular physical exercise can provide benefits without causing stress. Furthermore, exercise can improve hippocampal memory mediators ${ }^{23}$; swimming as an exercise can have a positive effect on cortisol and adrenaline levels ${ }^{24,25}$.

According to the literature, early life stress may be an essential risk factor for HPA axis disturbance ${ }^{26}$, and this can lead to depressive and anxiety disorders in adults ${ }^{27}$. This reveals the importance of physical activity in early life with many benefits such as preventing brain disorders ${ }^{28}$.

Additionally, the biochemical aspects of rats can produce changes after physical activity. A recent study concluded that 21 days of exercise without rest would have effects on biochemical factors in the brain and on memory function ${ }^{29}$. Moreover, exercise alters both bone modeling and energy balance ${ }^{22}$.

The main limitations of our study are the small sample size and the gender specificity, as we only included female Wistar rats. Due to these two limitations, our results are not applicable for both genders and the small 
sample size could impact the statistical analyse, particularly statistical significance.

\section{CONCLUSION}

We observed a significant reduction in body temperature of female Wistar rats after exposure to physical stress (forced swimming) in response to the body's stress and adaptation to the environment. Additionally, after the forced swimming for 21 days, the level of cortisol decreased for $60-90 \mathrm{~min}$, as compared to that of the control group. Our study was gender-specific. These results will help develop nonpharmacological therapy for neuropathic and musculoskeletal pain and enhance our understanding of the effects of exercise in our daily lives.

\section{ABBREVIATIONS}

LSD: least significant difference test

HPA: hypothalamic pituitary adrenal axis

SD: standard deviation

\section{ACKNOWLEDGMENTS}

We would like to thank Faculty of Natural Sciences and Mathematics, Institute of Biology, Skopje, North Macedonia for helping to conduct the experiment.

\section{AUTHOR'S CONTRIBUTIONS}

All authors contributed equally in the preparation of the manuscript. AIG, IG, VZ oversee this project, had full access and responsibility of the data. Study Design: AIG, IG, VZ. Instruction on the use of instruments for the outcome measures used in this study: IG, VZ. Analysis and interpretation of data: IG, SG. Manuscript preparation: AIG, AA, VZ. Statistical Analysis: SG. All authors approved the final manuscript.

\section{FUNDING}

None

\section{AVAILABILITY OF DATA AND MATERIALS}

Data and materials used and/or analyzed during the current study are available from the corresponding author on reasonable request.

\section{ETHICS APPROVAL AND CONSENT TO PARTICIPATE}

Not applicable.

\section{CONSENT FOR PUBLICATION}

Not applicable.

\section{COMPETING INTERESTS}

The authors declare that they have no competing interests.

\section{REFERENCES}

1. Elizabetha A, Younga B, Abelsona J, Lightman SL. Cortisol pulsatility and its role in stress regulation and health. Froniters in Neuroendocrinology. 2004;25:69-76. PMID: 15571755. Available from: https://doi.org/10.1016/j.yfrne.2004.07.001.

2. Gambarana C. Experimental protocols for the study of stress in animals and humans. Nutrients, stress and medical disorders. (Eds) Yehuda $S$ and Mostofsky D Human press Inc Torowa. 2005;p. 21-30. Available from: https://doi.org/10. 1385/1-59259-952-4:021.

3. Nagaraja HS, Jaganathan PS. Forced swimming stress induced alterations in ingestive behaviour in rats. Ind J Physiol Pharmacol. 2003;47:1-5.

4. Patton KT, Thibodeau GA. The human body in health and disease. Canada: Elsevier Mosby. 2014;.

5. Pauli JR, Souza L, Rogatto G, Gomes R, Luciano E. Glycocorticoids and metabolic syndrome: please favor physical exercise in this pathophysiology. Rev port cien desp. 2006;6:217-228. Available from: https://doi.org/10.5628/rpcd.06.02.217.

6. Chen C, Nakagawa $S$, et al. The exercise-glicocoticoid paradox: How exercise is beneficial for cognition, mood, and the brain while increasin glucocorticoid levels. Frontiers in Neuroendocrinology. 2017;44:83-102. PMID: 27956050. Available from: https://doi.org/10.1016/j.yfrne.2016.12.001.

7. Brown EJ, Vosloo A. The involvement of the hypothalamopituitary-adrenocortical axis in stress physiology and its significance in the assessment of animal welfare in cattle. Onderstepoort J Vet res. 2017;28(84):e1-e9. PMID: 28470085. Available from: https://doi.org/10.4102/ojvr.v84i1.1398.

8. Korte SM, et al. The Darwinian concept of stress: benefits of allostasis and costs of allostatic load and the trade-offs in health and disease. Neurosci Biobehav Rev. 2005;29(1):3-38. PMID: 15652252. Available from: https://doi.org/10.1016/j.neubiorev. 2004.08.009.

9. Pembrey MS. The Effect of Variations in External Temperature upon the Output of Carbonic Acid and the Temperature of Young Animals. J Physiolo. 1895;18(4):363-379. PMID: 16992261. Available from: 10.1113/jphysiol.1895.sp000573.

10. MacLeod JR. Observations on the excertion of carbon dioxide gas and the rectal temperature of rats kept in a warm atmosphere which was either very moist or very dry. Amer J Physiol .1907;18:1-18. Available from: .

11. Vinkers $\mathrm{CH}$, Groenink $\mathrm{L}$, et al. Stress-induced hyperthermia and infection-induced fever: two of a kind? Physiol Behav. 2009;98(1-2):37-43. PMID: 19375439. Available from: https: //doi.org/10.1016/j.physbeh.2009.04.004.

12. Busnardo $C$, et al. Paraventricular nucleus modulates autonomic and neuroendocrine responses to acute restraint stress in rats. Auton Neurosci. 2010;158(1-2):51-57. PMID: 20594922. Available from: https://doi.org/10.1016/j.autneu.2010.06.003.

13. Seo $\mathrm{H}$, et al. Effects of voluntary exercise on apoptosis and cortisol after chronic restraint stress in mice. J exerc Nutrition biochem. 2016;20(3):016-023. PMID: 27757383. Available from: https://doi.org/10.20463/jenb.2016.09.20.3.3.

14. Radahmadi M, et al. Stress boimarker responses to different protocols of forced exercise in chronically stressed rats. Journal of Bodywork \& Movement Therapies. 2017;21(1):6368. PMID: 28167192. Available from: https://doi.org/10.1016/j. jbmt.2016.05.002.

15. Soria M, Gonzalez-Haro C, et al. Plasamm leveles of trace elements and exercise induced stress homones in well-trained athletes. Journal of Trace elements in Medicine and Biology. 2015;31:113-119. PMID: 26004901. Available from: https: //doi.org/10.1016/j.jtemb.2015.04.004. 
16. Zschucke $E$, Renneberg B. The stress-buffering effect of acute exercise: evidence for HPA axis negative feedback. Psychoneuroendocrinology. 2015;51:414-425. PMID: 25462913. Available from: https://doi.org/10.1016/j.psyneuen. 2014.10.019.

17. Koulmann N, Richard-Bulteau $\mathrm{H}$, et al. Physical exercise during muscle regeneration improves recovery of the slow/oxidative phenotype. Muscle Nerve. 2017;55(1):91-100. PMID: 27104889. Available from: https://doi.org/10.1002/mus. 25151.

18. Strasser B, Fuchs D. Role of physical activity and diet on mood, behavior, and cognition. Neurology, Psychiatry and brain Research. 2015;21(3):118-126. Available from: https://doi.org/ 10.1016/j.npbr.2015.07.002.

19. Mazzardo-Martins L, Martins DF, et al. High-intensity extended swiming exercisereduces pain-related behaviour in mice: involvement of endogenous opioid and the serotonergic system. Journal of pain. 2010;11(12):1384-1393. PMID: 20488763. Available from: https://doi.org/10.1016/j.jpain. 2010.03.015.

20. Geisser ME, Wang W, et al. Nociception before and after exercise in rats bred for high and low aerobic capacity. Neuroscience letters. 2008;443:37-40. PMID: 18657596. Available from: https://doi.org/10.1016/j.neulet.2008.07.040.

21. Corazza DI, et al. Influence of chronic exercise on serum cortisol levels in older adults. Eur Rev Aging Phys Act. 2014;11:2534. Available from: https://doi.org/10.1007/s11556-013-01268.

22. Rosa BV, et al. Short-term voluntary exercise in the rat causes bone modeling without initiating a physiological stress response. Am J Physiol regul Integr Comp Physiol. 2010;299(4):R1037-R1043. PMID: 20668232. Available from: ttps://doi.org/10.1152/ajpregu.00112.2010.

23. Radahmadi $M$, et al. The Effect of Preventive, Therapeutic and Protective Exercises on Hippocampal Memory Mediators in Stressed Rats. Malays J Med. 2016;23(5):29-37. PMID: 27904422. Available from: https://doi.org/10.21315/ mjms2016.23.5.4.

24. Gashi Al, et al. Regular physical activity may influnece stress hormone cortisol innWistar rats. Journal of Physical Education and Sport. 2020;20(1):138 -141. Available from: https://doi org/10.7752/jpes.2020.01018.

25. Gashi Al, et al. The Effect of Aerobic Physical Activity in Adrenaline Level in White Laboratory Rats. 2020;74(2):8489. PMID: 32577046 . Available from: https://doi.org/10.5455/ medarh.2020.74.84-89.

26. Gunnar MR, et al. Developmental changes in hypothalamuspituitary-adrenal activity over the transition to adolescence: Normative Changes and association with puberty. Development and Psychopatology. 2009;21:69-85. PMID: 19144223. Available from: https://doi.org/10.1017/S0954579409000054.

27. Jones PB. Adult mental health disorders and their age at onset. The British Journal of pschiatry supplement. 2013;54:5510. PMID: 23288502. Available from: ttps://doi.org/10.1192/ bjp.bp.112.119164.

28. da Silva SG, et al. Early physical activity and seizures susceptibility later in life. Int J Dev neurosci. 2011;29(8):861-865. PMID: 21840389. Available from: https://doi.org/10.1016/j.ijdevneu. 2011.07.011.

29. Radamhadi $M$, et al. Effects of different timing of stress on corticosterone, BDNF and memory in male rats. Physiol Behav. 2015a;139:459-467. PMID: 25481360. Available from: https: //doi.org/10.1016/j.physbeh.2014.12.004. 